Supporting Information (ESI) for

"Tracing Local Nanostructure of the Aqueous Solutions of the Biocompatible [Cho][Gly] Ionic Liquid: Importance of Hydrogen Bond Attraction Between

\title{
Like-Charged Ions"
}

\author{
Farzad Khorrami ${ }^{1}$, Mohammad H. Kowsari ${ }^{1,2, *}$ \\ ${ }^{1}$ Department of Chemistry, Institute for Advanced Studies in Basic Sciences (IASBS), \\ Zanjan 45137-66731, Iran \\ ${ }^{2}$ Center for Research in Climate Change and Global Warming (CRCC), Institute for Advanced Studies in \\ Basic Sciences (IASBS), Zanjan 45137-66731, Iran
}

*Corresponding author: Tel.: +98 243315 3207, Fax: +98 2433153232.

E-mail address: mhkowsari@iasbs.ac.ir and mohammad.kowsari@gmail.com

ORCID Mohammad H. Kowsari: 0000-0003-4391-194X 


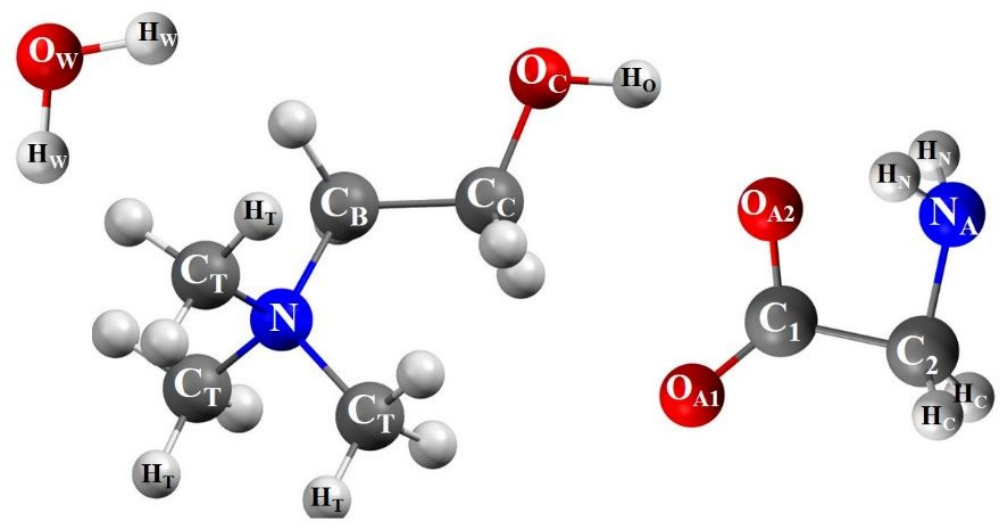

Figure S1. The molecular structure and atom-labeling scheme for the [Cho][Gly] IL and water.
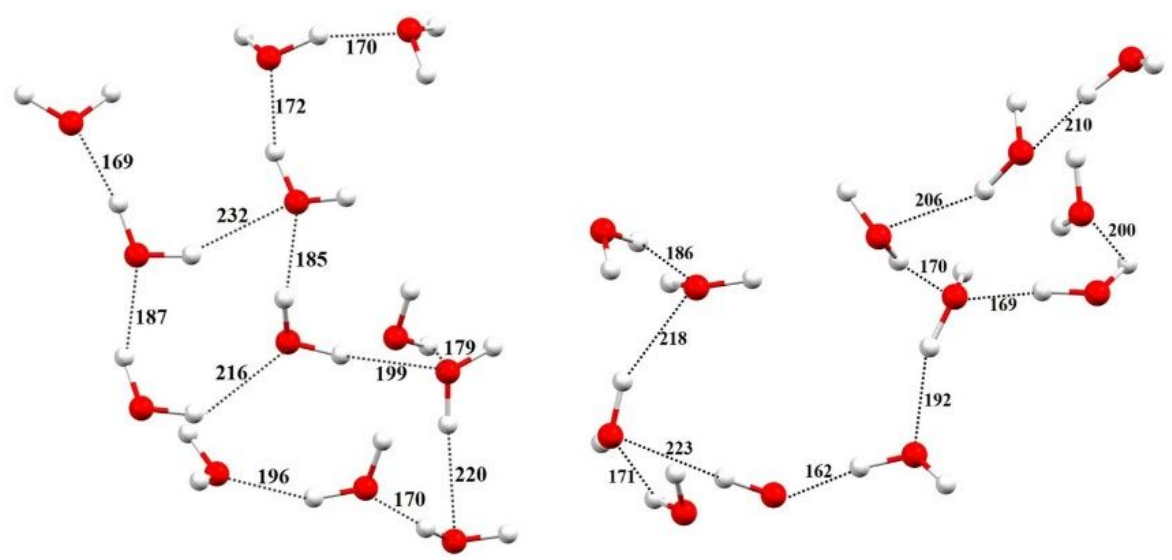

Figure S2. Selected snapshots of two branched water clusters from the equilibrated simulation box of the mixture with $x_{\mathrm{w}}=0.75$. These clusters often cannot be placed in the cavities between the ions, and therefore in Figure 1a of the main text of manuscript, we see a decrease in the mixture density in this $x_{\mathrm{w}}$. The $\mathrm{O} \cdots \mathrm{H}$ intermolecular distances in bold black are inserted (in pm) for more clarification. 
Section S1. Tracing cation-anion H-bonds in neat IL using the combined RDF and ADF analysis

To investigate the H-bond distance criterion of the hydroxyl hydrogen $\left(\mathrm{H}_{\mathrm{O}}\right)$ site of $[\mathrm{Cho}]^{+}$relative to the carboxylate oxygen atoms $\left(\mathrm{O}_{\mathrm{A} 1}\right.$ and $\left.\mathrm{O}_{\mathrm{A} 2}\right)$ of the reference [Gly]-, we have used a CDF constructed from the distances of $\left(\mathrm{H}_{\mathrm{O}}-\mathrm{O}_{\mathrm{A} 2}\right)$ versus $\left(\mathrm{H}_{\mathrm{O}}-\mathrm{O}_{\mathrm{A} 1}\right)$ as shown in Figure $\mathrm{S} 3 \mathrm{a}$. Both distances fulfill the distance criterion of this $\left[\mathrm{Cho}^{+}-[\mathrm{Gly}]^{-} \mathrm{H}-\right.$ bond. However, it can be observed that the more probable $\mathrm{H}$-bond formation of $\left(\mathrm{H}_{\mathrm{O}^{-}}-\mathrm{O}_{\mathrm{A} 2}\right)$ at the shorter distances compared to $\left(\mathrm{H}_{\mathrm{O}^{-}}\right.$ $\left.\mathrm{O}_{\mathrm{A} 1}\right)$ based on an intense asymmetric occurrence probability region at $\left(\mathrm{r}_{1}=200 \mathrm{pm}\right.$ and $\mathrm{r}_{2}=200$ $400 \mathrm{pm})$.

To investigate the local cation-anion arrangement, we defined a respective CDF as shown in Figure S3b to confirm the geometric conditions of H-bond formation between the hydroxyl hydrogen $\left(\mathrm{H}_{\mathrm{O}}\right)$ site of $[\mathrm{Cho}]^{+}$and a carboxylate oxygen atom $\left(\mathrm{O}_{\mathrm{A} 2}\right)$ of $[\mathrm{Gly}]^{-}$.

There are partial negative charges on the amine $\mathrm{N}_{\mathrm{A}}(\sim-0.876 e)$ and the carboxylate $\mathrm{O}_{\mathrm{A}}(\sim-$ $0.815 e$ and $-0.702 e$ ) atoms of [Gly] ${ }^{-}$and the positive charges on the trimethyl-amine group (with $\left.q_{\mathrm{N}}=+0.228 e\right)$, the $\mathrm{H}_{\mathrm{O}}$ atom $(+0.469 e)$, and the $\mathrm{C}_{\mathrm{C}}$ atom $(+0.527 e)$ of $[\mathrm{Cho}]^{+}$in the applied force field with charge scaling factor of 0.80 . Key partial positive charge centers exist on the nitrogen (N) and $\mathrm{H}_{\mathrm{O}}$ atoms of $[\mathrm{Cho}]^{+}$and main negative charges are on the amine $\mathrm{N}_{\mathrm{A}}$ and the carboxylate $\mathrm{O}_{\mathrm{A}}$ atoms of $[\mathrm{Gly}]^{-}$. Therefore, to determine the preferred cation-anion arrangement, we have also combined two $\left(\mathrm{N}-\mathrm{N}_{\mathrm{A}}\right)$ and $\left(\mathrm{N}-\mathrm{O}_{\mathrm{A}}\right)$ RDFs with high occurrence probability region around distances of $600 \mathrm{pm}$ and $400 \mathrm{pm}$, respectively. The preferred orientations of [Cho] $]^{+}$to [Gly] includes of the $\left(\mathrm{N}-\mathrm{O}_{\mathrm{A}}\right)$ structural correlation in addition to the $\left(\mathrm{H}_{\mathrm{O}}-\mathrm{O}_{\mathrm{A} 2}\right) \mathrm{H}$-bond.

As a new finding, the CDF in Figure S3c and a segment of final snapshot of the equilibrated simulation box in Figure $\mathrm{S} 3 \mathrm{~d}$ showed that the $\left(\mathrm{N}-\mathrm{O}_{\mathrm{A}}\right)$ cation-anion structural correlation is due to 
the $\left(\mathrm{H}_{\mathrm{T}}-\mathrm{O}_{\mathrm{A}}\right) \mathrm{H}$-bonds between the methyl hydrogen $\left(\mathrm{H}_{\mathrm{T}}\right)$ and the carboxylate oxygen $\left(\mathrm{O}_{\mathrm{A}}\right)$ pairs. As shown in Figure S3d, a segment of several cation-anion neighbors confirms existing of both the $\mathrm{H}_{\mathrm{O}}{ }^{[\mathrm{Cho}]^{+}-} \mathrm{O}_{\mathrm{A}}[\mathrm{Gly}]-$ and $\mathrm{H}_{\mathrm{T}}[\mathrm{Cho}]^{+}-\mathrm{O}_{\mathrm{A}}{ }^{[\mathrm{Gly}]}$ - cation-anion structural correlations as well as the $\mathrm{H}_{\mathrm{T}}-\mathrm{O}_{\mathrm{C}}$ cation-cation preferred structural correlations. The latter also is confirmed in Figure $5 \mathrm{c}$ of the main text of manuscript.
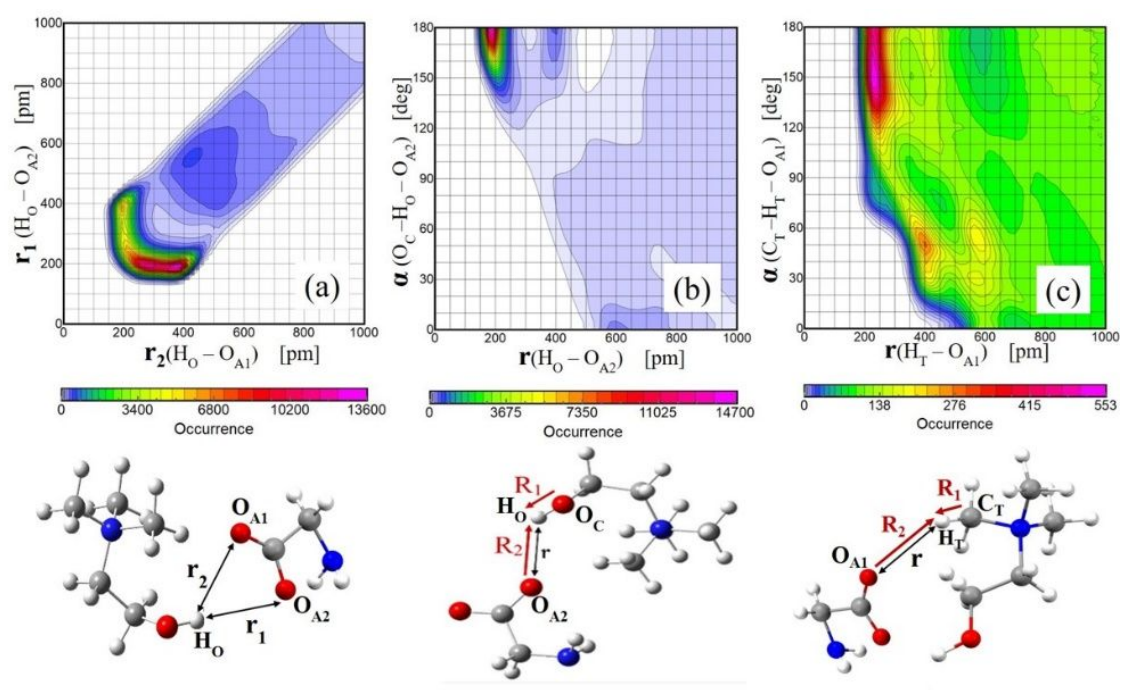

(d)
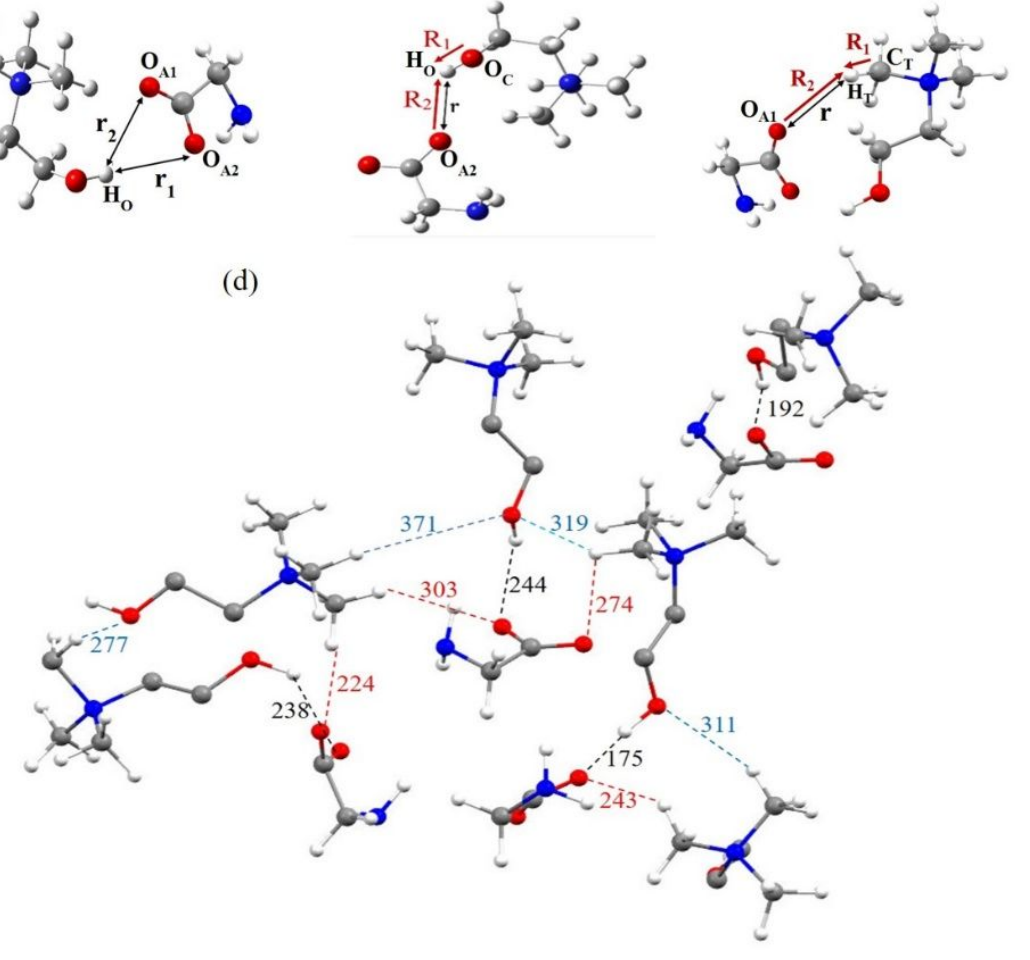

Figure S3. Two body orientation analysis of adjacent counterions relative to each other. (a) The constructed $\mathrm{CDF}$ of the $\left(\mathrm{H}_{\mathrm{O}}-\mathrm{O}_{\mathrm{A} 1}\right)$ versus $\left(\mathrm{H}_{\mathrm{O}}-\mathrm{O}_{\mathrm{A} 2}\right)$ distances, (b) and (c) The constructed CDFs include of the defined angle between $\mathrm{R}_{1}$ and $\mathrm{R}_{2}$ vectors versus the $\left(\mathrm{H}_{\mathrm{O}}-\mathrm{O}_{\mathrm{A} 2}\right)$ or the $\left(\mathrm{H}_{T}-\mathrm{O}_{\mathrm{A} 1}\right)$ distances, respectively, (d) A segment of the nearest neighbors of counterions in pure [Cho][Gly] IL that are extracted from the final snapshot of the equilibrated simulation box. The $\left(\mathrm{H}_{\mathrm{O}}-\mathrm{O}_{\mathrm{A}}\right),\left(\mathrm{H}_{\mathrm{T}}-\right.$ $\left.\mathrm{O}_{\mathrm{A}}\right)$, and $\left(\mathrm{H}_{\mathrm{T}}-\mathrm{O}_{\mathrm{C}}\right)$ intermolecular distances in black, red, and blue are inserted in pm, respectively, for more clarification. 
Section S2. Effect of water concentration on the mutual orientation of neighboring [Cho] ${ }^{+}$

cations using the combined RDF and ADF analysis
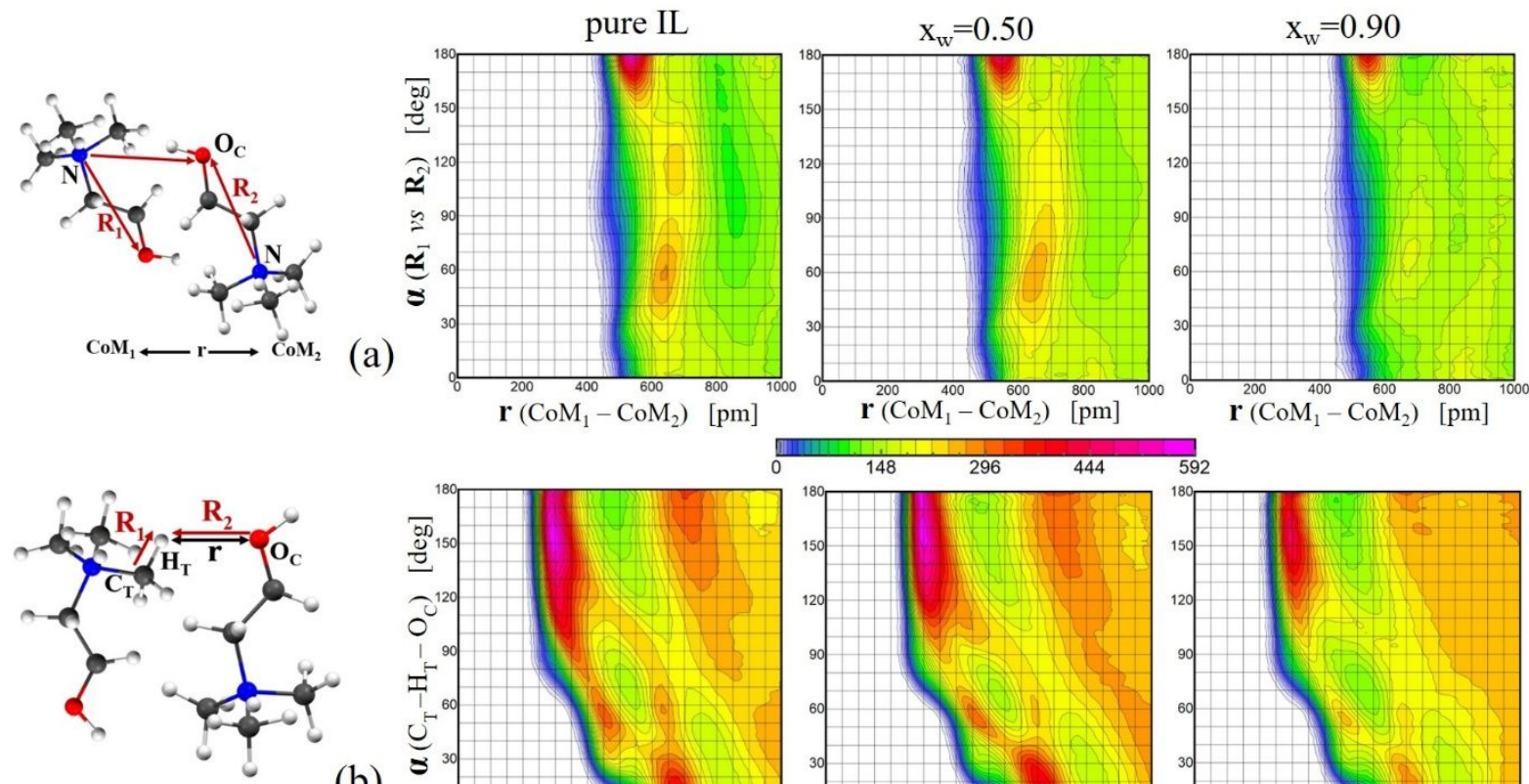

(b)
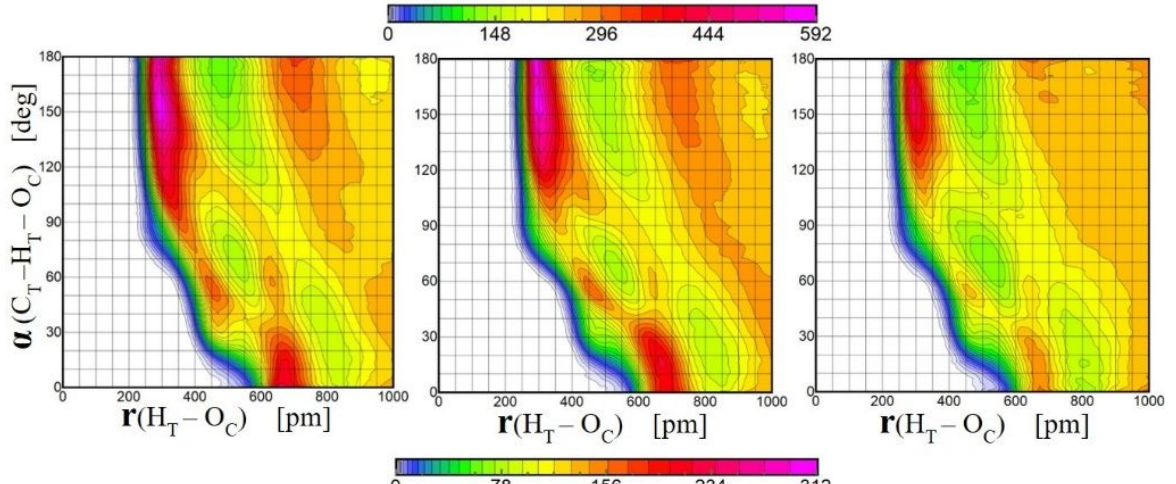

Figure S4. Effect of water addition on the defined angular/distance CDFs that corresponding to (a) the mutual orientation of neighboring [Cho] ${ }^{+}$cations with the definition of aangle between $\left(\mathbf{R}_{\mathbf{1}}\right.$ and $\mathbf{R}_{\mathbf{2}}$ ) vectors versus the COM-COM distances ( $\mathbf{r}$ ) of neighboring cations, (b) the constructed $\left(\mathrm{H}_{\mathrm{T}}-\mathrm{O}_{\mathrm{C}}\right) \mathrm{H}$-bonds between adjacent $[\mathrm{Cho}]^{+}$cations. 
Table S1. Applied criteria for considering the different types of H-bonds.

\begin{tabular}{ccc} 
H-bond & \multicolumn{2}{c}{ Criteria } \\
\cline { 2 - 3 } Type & Distance $^{*}[\mathrm{pm}]$ & Angle [deg.] \\
$\mathrm{H}_{\mathrm{O}^{---} \mathrm{O}_{\mathrm{A}}}$ & 325 & 135 \\
$\mathrm{H}_{\mathrm{O}}---\mathrm{O}_{\mathrm{W}}$ & 275 & 135 \\
$\mathrm{H}_{\mathrm{W}}--\mathrm{O}_{\mathrm{A}}$ & 225 & 150 \\
$\mathrm{H}_{\mathrm{W}}---\mathrm{O}_{\mathrm{W}}$ & 225 & 150 \\
$\mathrm{H}_{\mathrm{T}}---\mathrm{O}_{\mathrm{C}}$ & 350 & 120 \\
$\mathrm{H}_{\mathrm{C}}---\mathrm{N}_{\mathrm{A}}$ & 350 & 120
\end{tabular}

* The distance criterion for calculating each type of $\mathrm{H}$-bonding is chosen as the first minima of the related RDFs. 


\section{Section S3. The calculated IR spectra from DFT calculation}



Figure S5. The calculated IR spectra for three different IL-related systems by using DFT calculations

The QM calculations are performed for three systems that are the corresponded simple models of our MD simulations for the pure IL and the binary mixture with $x_{\mathrm{w}}=0.75$.

System 1: Includes one ion pair of $[\mathrm{Cho}]^{+}$and $[\mathrm{Gly}]^{-}$(a simple model of the pure IL)

System 2: Includes one [Cho] $]^{+}$and 3 water molecules. (a simple model of the hydrated cation) System 3: Includes one [Gly] $]^{-}$and 3 water molecules. (a simple model of the hydrated anion)

The wavenumbers of main vibrational modes of the functional groups that associated with H-bonds in the three studied systems are listed in Table S2. According to the computed data in Table S2, changing system 1 (pure IL) to systems 2 and 3 (the mixture with $x_{\mathrm{w}}=0.75$ ) causes to shift in the 
position of wavenumbers of different vibrational modes for the key functional groups. It can be seen that by changing the participant species (from the anion to water) that form the H-bond with the cation, a blue $\left(211 \mathrm{~cm}^{-1}\right)$ and red shifts $\left(109 \mathrm{~cm}^{-1}\right)$ were observed for the stretching and bending vibrational modes of hydroxyl $\left(\mathrm{O}_{\mathrm{C}}-\mathrm{H}_{\mathrm{O}}\right)$ group of $[\mathrm{Cho}]^{+}$. On the other hand, it can be seen that the alteration of the H-bond partner species of the anion (from the cation in the pure IL to the water in the system with $x_{\mathrm{w}}=0.75$ ) causes a slight shift on the stretching vibrational modes of the $\mathrm{N}_{\mathrm{A}}-\mathrm{H}_{\mathrm{N}}$ and $\mathrm{C}_{2}-\mathrm{O}_{\mathrm{A}}$ of $[\mathrm{Gly}]$. This result indicates that the H-bond strength of the anion-cation $\left(\mathrm{O}_{\mathrm{A}} \cdots \mathrm{H}_{\mathrm{O}}\right)$ and the anion-water $\left(\mathrm{O}_{\mathrm{A}} \cdots \mathrm{H}_{\mathrm{W}}\right)$ is roughly similar, while the H-bond strength of the cation-water $\left(\mathrm{H}_{\mathrm{O}} \cdots \mathrm{O}_{\mathrm{W}}\right)$ is weaker than that of the cation-anion $\left(\mathrm{H}_{\mathrm{O}} \cdots \mathrm{O}_{\mathrm{A}}\right)$ case.

Table S2. Wavenumbers ( $\bar{v}$ in $\left.\mathrm{cm}^{-1}\right)$ of the main vibrational modes of the IR spectra for [Gly] and $[\mathrm{Cho}]^{+}$from the DFT calculations of the three studied cases.

\begin{tabular}{|l|c|c|c|c|}
\hline \multicolumn{1}{|c|}{ system } & $\begin{array}{c}\bar{v}\left(\mathrm{~cm}^{-1}\right) \\
\text { stretching } \\
\mathrm{N}_{\mathrm{A}}-\mathrm{H}_{\mathrm{N}}\end{array}$ & $\begin{array}{c}\bar{v}\left(\mathrm{~cm}^{-1}\right) \\
\text { stretching } \\
\mathrm{C}_{2}-\mathrm{O}_{\mathrm{A}}\end{array}$ & $\begin{array}{c}\bar{v}\left(\mathrm{~cm}^{-1}\right) \\
\text { stretching } \\
\mathrm{O}_{\mathrm{C}}-\mathrm{H}_{\mathrm{O}}\end{array}$ & $\begin{array}{c}\bar{v}\left(\mathrm{~cm}^{-1}\right) \\
\text { bending } \\
\mathrm{O}_{\mathrm{C}}-\mathrm{H}_{\mathrm{O}}\end{array}$ \\
\hline$[\mathrm{Cho}]^{+}+[\mathrm{Gly}]^{-}$ & $3491 / 3554^{*}$ & $1413 / 1604$ & 3118 & 869 \\
\hline$[\mathrm{Cho}]^{+}+3 \mathrm{H}_{2} \mathrm{O}$ & --- & --- & 3329 & 760 \\
\hline$[\mathrm{Gly}]^{-}+3 \mathrm{H}_{2} \mathrm{O}$ & $3468 / 3531$ & $1411 / 1629$ & --- & --- \\
\hline
\end{tabular}

* Wavenumbers of the symmetric/asymmetric vibrational modes
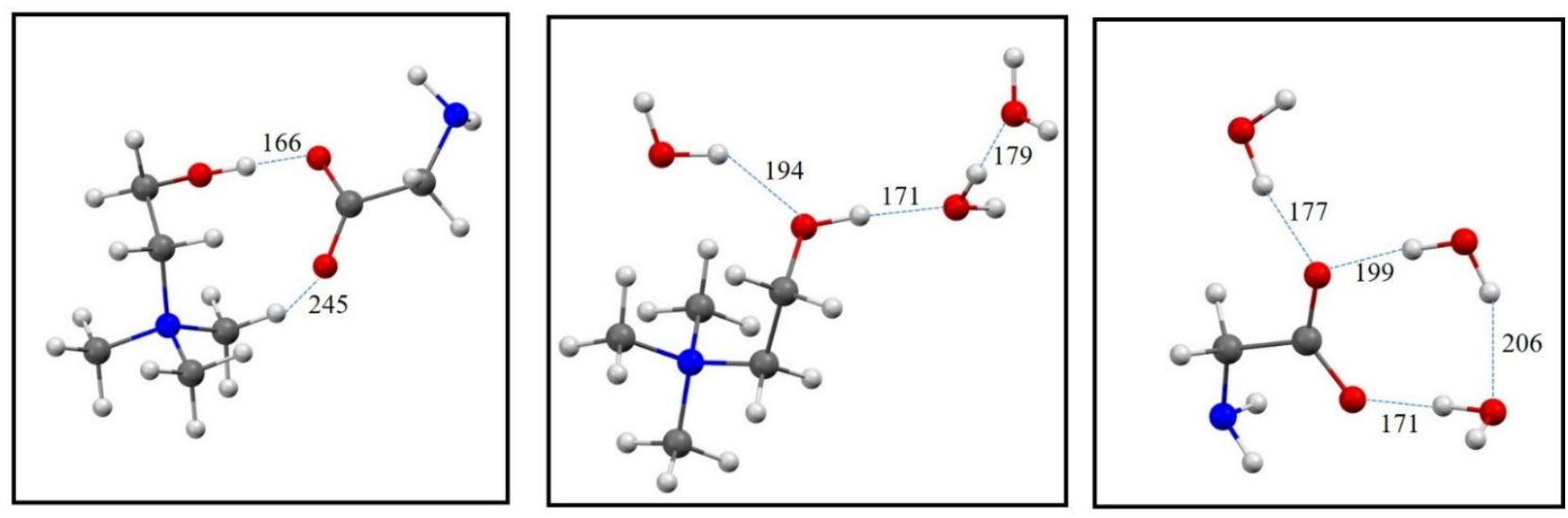

Figure S6. The Optimized geometries at the B3LYP/6-311++G** level of theory for the three studied systems: a single ion pair of [Cho][Gly], $\left([\mathrm{Cho}]^{+}+3 \mathrm{H}_{2} \mathrm{O}\right)$, and $\left([\mathrm{Gly}]^{-}+3 \mathrm{H}_{2} \mathrm{O}\right)$. The different $(\mathrm{H} \cdots \mathrm{O})$ intermolecular distances are inserted (in $\mathrm{pm})$ for more clarification. 